\title{
Steroid contents of and steroidogenesis in vitro by the developing gonad and mesonephros around sexual differentiation in fetal sheep
}

\author{
S. Lun, P. Smith, T. Lundy, A. O'Connell, N. Hudson and K. P. McNatty* \\ Wallaceville Animal Research Centre, PO Box 40063, Upper Hutt, New Zealand
}

\begin{abstract}
The aim of the present study was to establish whether the steroids, progesterone, androstenedione, testosterone and oestradiol, were present in the mesonephricgonadal complex of female and male sheep fetuses around sexual differentiation (that is, from day 28 to day 45 of gestation, with sexual differentiation occurring at approximately day 32). A second aim was to test whether the mesonephric-gonadal complex, mesonephros (days 35-45 only) and gonad (days 35-45 only) were capable of steroid synthesis in vitro. The steroid contents in the mesonephric-gonadal complex were not detectable before sexual differentiation. However, from day 35 of gestation onwards, the mesonephric-ovarian complex contained mainly oestradiol and the mesonephric-testicular complex contained mainly testosterone: from day 35 until day 45 the increase in content of these two steroids exceeded the increase in the mass of tissue by more than fivefold. From day 40 to day 45 of gestation, the contents of the other steroids in the pathways to oestradiol increased progressively in both sexes but more in parallel with the increase in tissue mass. In contrast to the steroid contents in the tissue at recovery, the mesonephric-gonadal tissue from both sexes in tissue culture was able to synthesize most steroids before and after sexual differentiation and also to metabolise supplementary androstenedione to oestradiol. These findings suggest that many, if not all, of the steroidogenic enzymes in the pathway from cholesterol to oestradiol are present before sexual differentiation. Most of the aforementioned steroids were present in detectable amounts in isolated mesonephros and gonad of both sexes after sexual differentiation. Moreover, for both the isolated mesonephros and gonad, there were increases in the mean contents of most steroids after culture relative to the contents in the tissues at recovery. These data suggest that the mesonephros, as well as the gonad, in both sexes is capable of synthesizing steroid. It is concluded that, in the sheep fetus, the female and male gonads are steroidogenically active after sexual differentiation, that the steroidogenic enzymes develop before sexual differentiation, and that the mesonephros is a site of steroid synthesis.
\end{abstract}

\section{Introduction}

In the sheep fetus, gonadal sex differentiation occurs around days 29-32 of fetal life (Zamboni and Upadhyay, 1982; McNatty et al., 1995). The gonad develops at the surface of the mesonephros and is formed from three principal cell types: (1) the coelomic epithelium; (2) cells of the mesonephros; and (3) germ cells (for review, see Peters and McNatty, 1980). Around the time of sexual differentiation and until the onset of germ cell meiosis (at approximately day 55), a confluent mass of cells can be observed from a region of the mesonephros adjacent to the giant glomeruli extending deep into the gonad (Zamboni, et al., 1979; Zamboni and Upadhyay, 1982; McNatty et al., 1995). It has been proposed that these cells of mesonephric origin

*Correspondence.

Received 24 December 1997. organize themselves progressively into semniferous cords, cords of the rete testis and the precursor steroidogenic cells (that is, Sertoli and Leydig cells) in males, whereas they contribute to the rete ovarii and also steroidogenic cells (that is, granulosa and theca cells) in females (Byskov, 1978; Buehr et al., 1993).

The gonads of many mammals around the time of sexual differentiation are known to synthesize steroids (for review, see George and Wilson, 1988). Although testosterone synthesis in the gonad is a prerequisite for expression of the male phenotype, oestradiol synthesis is not a prerequisite for the female phenotype (Jost, 1947, 1953). Nevertheless, it is possible that steroids in the ovary, as well as in the testis, are important for the cellular organization of the gonads. In sheep, some key prerequisites for gonadal steroidogenesis are present in the gonad, namely SF-1 mRNA from day 25 of fetal life, $3 \beta$-hydroxysteroid dehydrogenase in the putative male gonad from day 30 , and p450 aromatase mRNA from 
day 35 in the newly differentiated ovary (Payen ct al., 1996; Sweeney et al., 1997). There are also reports that the gonads of fetal sheep are capable of synthesizing steroids from about day 30 to day 50 of fetal life (Attal, 1969; Mauleon ct al., 1977). However, these results were sometimes derived from gonads of either unknown sex or from pools of gonads from both sexes. Therefore, in fetal sheep, there is a paucity of knowledge with respect to the actual steroid content and steroidogenic potential of the male or female gonad from before sexual differentiation until regression of the mesonephros. Moreover, given that the the steroidogenic cells in the gonads may be mesonephric in origin, there is a lack of knowledge as to whether the mesonephros itself has a capacity for steroidogenesis.

The purpose of the present study was to establish whether the steroids, progesterone, androstenedione, testosterone and oestradiol are present in the mesonephric-gonadal complex of both male and female fetuses from day 28 until day 45 of gestation and to test whether this complex was capable of synthesizing the aforementioned steroids. A second aim was to test whether the mesonephros and gonad were individually capable of steroid synthesis in itro.

\section{Materials and Methods}

The experimental procedures reported in this study were carried out in accordance with the 1987 Animal Protection (Codes of Ethical Conduct) Regulations of New Zealand after approval was granted by the Animal Ethics Committee of the Wallaceville Animal Research Centre.

\section{Animals and procedures}

Fetuses were recovered from pregnant Romney ewes after superovulation of Romney ewes, natural mating, embryo recovery and transfer to recipient animals. The purpose of undertaking this procedure was to maximize the number of fetuses and to minimize the number of recipient pregnant ewes to be killed. The donor ewes were superovulated using pregnant mares' serum gonadotrophin (PMSG; Folligon; Intervet, Castle Hill, NSW) and ovine FSH (Ovagen; Immuno-Chemical Products Ltd, Auckland; $20 \mathrm{ml}$ vial is equivalent to $18 \mathrm{mg}$ NIADDK-oFSH-17 as assessed by radioreceptor assay). The donor ewes $(n=42)$ were fitted with intravaginal progesterone devices (CIDR-s type G; $\mathrm{AHI}$ Plastic Moulding Co., Hamilton) for 10 days (day of CIDR-s implant, day 0 ). On day 10 , the CIDR-s device was replaced and the ewes were given an i.m. injection of $300 \mathrm{iu}$ PMSG and $8 \times 1 \mathrm{ml}$ injections (i.m.) of a $20 \mathrm{ml}$ ampoule of FSH starting from the time of PMSG injection (morning) and thereafter at intervals of $12 \mathrm{~h}$. The second CIDR-s device was removed on the morning of day 13. On the evening of day 13 and on the morning of day 14 the ewes were mated with sexually active Romney rams $(n=12)$. Four to five days after mating embryos were recovered. Oestrus-synchronized (with CIDR-s) Romney ewes each received three embryos using a laparoscopic technique. At days 28, 30, 32, 35, 40 and 45 after mating the fetuses $(n=211)$ were recovered after a barbiturate overdose was given to their mothers (injection of approximately $20 \mathrm{ml}$ i.v. of $500 \mathrm{mg}^{-}$Euthatal ml-1; Chemstock, Palmerston North). The gonads or mesonephros or both were dissected out and weighed before use in the present study. In addition, the hind quarters were removed and fixed in paraformaldehyde for subsequent paraffin wax embedding and sex determination.

\section{Sexing fetuses}

The sex of the fetuses both before and after sexual differentiation was determined by PCR analysis with Sryspecific primers. DNA was extracted from $3 \times 5 \mu \mathrm{m}$ paraffin wax sections of fetal hind limb (Sarkar et al., 1993) using a $10 \mathrm{mmol}$ Tris-HCl $\mathrm{l}^{-1}$ lysis buffer ( $\mathrm{pH}$ 7.5) containing 50 mmol $\mathrm{HCl} \mathrm{l}^{-1}, 2.5 \mathrm{mmol} \mathrm{MgCl}_{2} \mathrm{l}^{-1}, 0.45 \%$ (v/v) Tween 20 and proteinase $\mathrm{K}\left(0.5 \mathrm{mg} \mathrm{ml}^{-1}\right)$. The Sry-specific primers were: forward CAT TGT GTG GTC TCG TGA ACG and reverse GTC TCG GTG TAT AGC TAG TAG. After the PCR procedure and agarose gel electrophoresis using molecular weight markers, the sex of the fetus was determined by the presence or absence of the male-specific $166 \mathrm{bp}$ band.

\section{Culture experiments}

Gonads (with or without mesonephros) were either frozen immediately or cultured to assess steroidogenic potential by methods described by McNatty et al. (1986). Three different experiments were performed: (1) intact mesonephros and gonad cultured; (2) intact mesonephros and gonad cultured in the presence of $1 \mu \mathrm{g}$ androstenedione $\mathrm{ml}^{-1}$; (3) mesonephros and gonad cultured separately. Briefly, the above tissues were placed on a strip of sterile filter paper and supported on a stainless steel grid above $1.8 \mathrm{ml}$ culture medium consisting of a 1:1 mixture of Hams F10 and Dulbecco's Modified Eagle Medium (Gibco BRL Life Technologies, Grand Island, NY) containing $20 \mathrm{mmol}$ Hepes buffer $\mathrm{l}^{-1}, 50 \mu \mathrm{g}$ gentamycin sulphate $\mathrm{ml}^{-1}, 100 \mathrm{U}$ nystatin $\mathrm{ml}^{-1}, 0.1 \%(\mathrm{w} / \mathrm{v})$ bovine serum albumin (ICP Ltd Auckland, Aukland) and $1 \mu \mathrm{g}$ bovine insulin $\mathrm{ml}^{-1}$ (Sigma Chemical Co., St Louis, MO) in a $35 \mathrm{~mm} \times 10 \mathrm{~mm}$ Petri dish (Falcon, Becton Dickinson, NJ). The Petri dishes were placed in an anaerobic jar (Oxoid Ltd, Basingstoke) and the air in the jar was replaced with a mixture of $50 \% \mathrm{O}_{2}, 45 \% \mathrm{~N}_{2}$ and $5 \% \mathrm{CO}_{2}$ to $70 \mathrm{kPa}$ pressure. The jar was placed in a $37^{\circ} \mathrm{C}$ incubator for $24 \mathrm{~h}$ and then medium was collected and replaced with 1.8 $\mathrm{ml}$ fresh medium. After a further $24 \mathrm{~h}$ incubation, the medium and tissue were collected and each stored separately at $-20^{\circ} \mathrm{C}$ until assayed for steroids.

\section{Steroid assays}

Progesterone, androstenedione, testosterone and oestradiol were measured directly in culture medium by radioimmunoassay. The gonad tissues were homogenized in

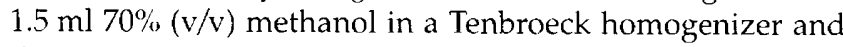
then centrifuged at $2500 \mathrm{~g}$. The supernatants were decanted 
into test tubes and dried in a vacuum centrifuge. Thereafter, the residues were dissolved in $1 \mathrm{ml}$ culture medium for assay.

Oestradiol and testosterone antisera, and ${ }^{125}$ I-labelled oestradiol, testosterone and androstenedione were purchased from Diagnostic Products Corporation, Los Angeles, CA. The oestradiol and testosterone antisera were further diluted 1:8 in phosphate gelatin assay buffer before use. Antisera for androstenedione (C-1462) and progesterone (C-9817) were purchased from Bioquest Ltd, Sydney, and progesterone-11 glucuronide-[ $\left.{ }^{[25} \mathrm{I}\right]$ iodotyramine tracer from Amersham, Buckinghamshire. The percentage crossreaction of steroids with the progesterone antisera relative to progesterone at $50 \%$ of zero binding was $22 \%$ for $11 \beta$ hydroxyprogesterone, $6.3 \%$ for $5 \beta$-pregnane- 3,20 -dione, $3.7 \%$ for 11 -deoxycorticosterone, $3 \%$ for $20 \beta$-hydroxy-4pregnene-3-one, $2 \%$ for pregnenolone and $<0.3 \%$ for testosterone, androstenedione and oestradiol. For the androstenedione antisera the percentage crossreactions were $30 \%$ for $5 \alpha$-androsten- $3 \beta$-ol- 17 -one, $33 \%$ for $5 \alpha$-androstan$3 \alpha$-ol-17-one, $3 \%$ for testosterone, $0.1 \%$ for oestrone, $<0.06 \%$ for oestradiol and $<0.01 \%$ for cortisol and progesterone. For testosterone, the major crossreacting steroid was $5 \alpha-$ dihydrostestosterone $(34 \%)$ whereas cross-reactions with androstenedione $(0.8 \%), 5 \beta$ dihydrostestosterone, $(<0.1 \%)$, progesterone $(<0.1 \%)$, oestrone $(<0.1 \%)$ and oestradiol $(<0.1 \%)$ were all very low. For oestradiol, the major crossreaction was with oestrone $(12.5 \%)$ while crossreactions with oestriol were low $(0.24 \%)$ and progesterone, androstenedione and testosterone were undetectable.

For assay, $100 \mu \mathrm{l}$ sample, $100 \mu \mathrm{l}$ antiserum and $100 \mu \mathrm{l}{ }^{125} \mathrm{I}-$ tracer were incubated overnight at $4^{\circ} \mathrm{C}$. Separation of free from bound was by the second antibody method using goat anti-rabbit IgG for testosterone and oestradiol or rabbit antisheep IgG (Sigma Chemical Co.) for progesterone and androstenedione, followed by $1 \mathrm{ml} 10 \%$ (w/v) PEG 8000, Carbowax (Union Carbide, Co., Danbury, CT, USA) and centrifugation.

In experiments in which androstenedione had been added to the culture medium, samples of this medium were assayed for oestradiol to determine the blank value (approximately $4 \mathrm{pg} \mathrm{ml}^{-1}$ ) that was subtracted from the culture values.

The sensitivities of the assays for progesterone, androstenedione, testosterone and oestradiol $(90 \%$ of zero binding value) were $10,20,5$ and $2 \mathrm{pg} \mathrm{ml}^{-1}$, respectively. Intra- and interassay coefficients of variations for each of the above assays were: $10.9 \%$ and $11.4 \%, 13.6 \%$ and $16.2 \%, 11.7 \%$ and $11.9 \%$, and $9.2 \%$ and $11.3 \%$, respectively.

\section{Statistical analysis}

Steroid values were log-transformed to equalize the variances. All values are presented as geometric means and $95 \%$ confidence limits. The steroid results for tissue culture are presented as the sum of steroid present in the tissue at the end of culture plus that present in the medium during the two consecutive $24 \mathrm{~h}$ of culture. A one sample Student's $t$ test was performed comparing the actual steroid value with a value which was $2 \mathrm{SD}$ above the detection limit of the assay to

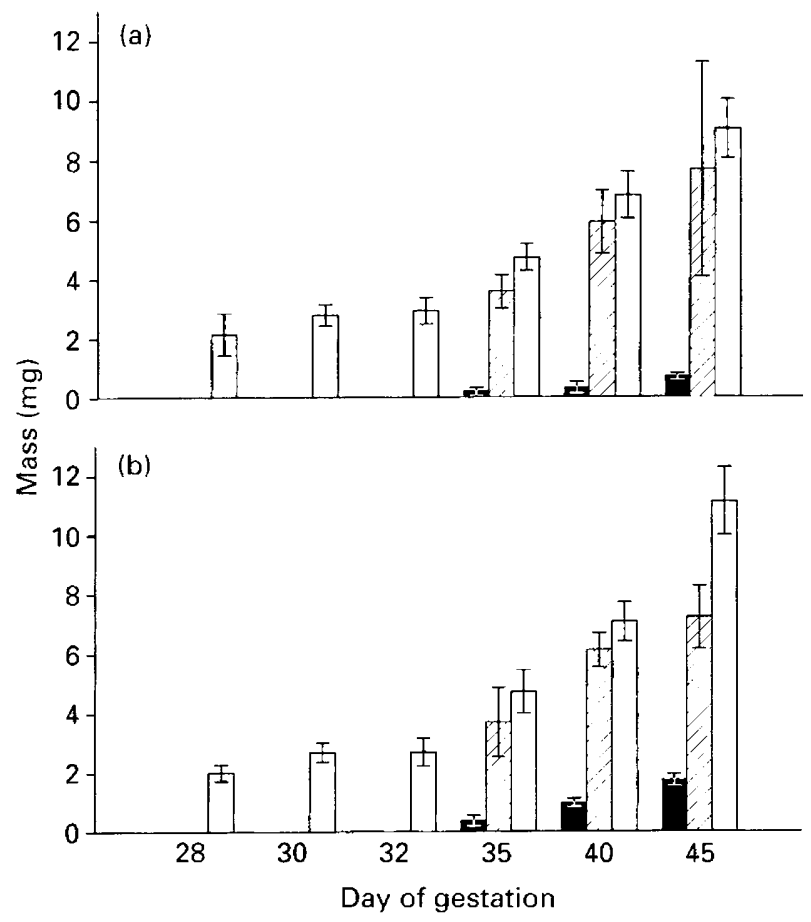

Fig. 1. Mass (mg) of gonad plus mesonephros ( $\square$ ), mesonephros ( [] ) and gonad ( $\boldsymbol{\square}$ ) with respect to day of gestation for (a) female and (b) female sheep fetuses. Values are geometric means and vertical bars represent $95 \%$ confidence limits.

test whether steroid contents were significantly different from the detection limit (this value of 2 SD was obtained from a knowledge of the detection limit and the interassay coefficient of variability of the assay). The effects of age were examined using analysis of variance (ANOVA) on logtransformed data.

\section{Results}

Changes in the mass of the mesonepliric-gonadal complex, and isolated mesonephros and gonad with respect to day of gestation and sex

These data are plotted as geometric means with $95 \%$ confidence limits (Fig. 1). It was not possible to clearly separate the mesonephros from the gonad before day 35 of gestation and therefore, results for the isolated tissues were obtained for only days 35,40 and 45 of gestation. An example of an intact and separated mesonephros-gonad complex before culture is shown (Fig. 2). There were significant effects of gestation age on the mass of the mesonephric-gonadal complex in both sexes $(P<0.01$, ANOVA $)$ and also on the mass of both organs separately $(P<0.01$, for both sexes and both the mesonephros and gonad separately). In essence, the mass of the mesonephric-gonadal complex in both sexes did not increase significantly from day 28 to day 32 but increased at days $35(P<0.01$ compared with days $28-32$, both sexes), $40(P<0.01$ compared with day 35$)$ and day $45(P<0.01$ compared with day 40 ). The progressive increase in the mass of the mesonephric-gonadal complex in males and females 

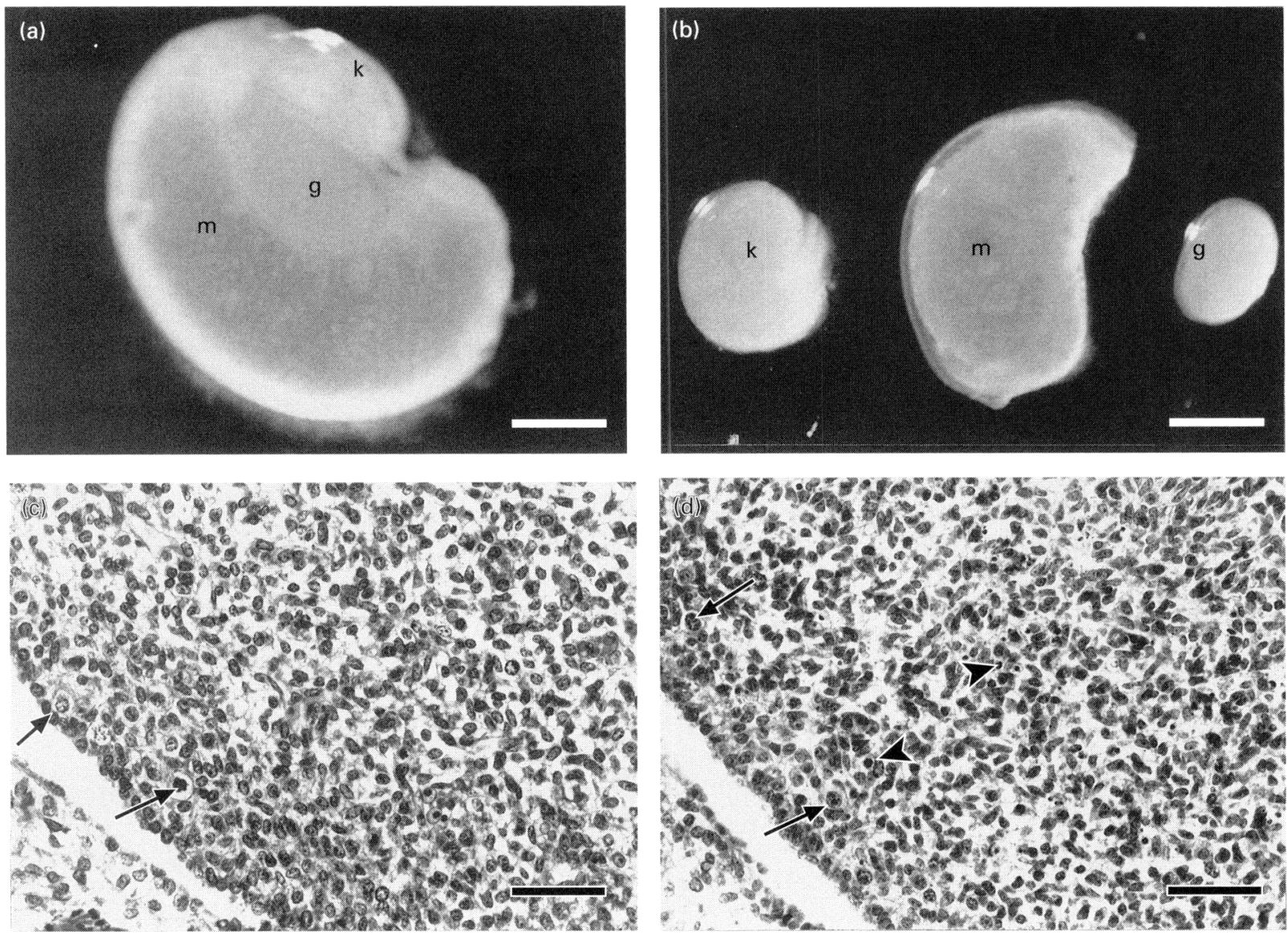

Fig. 2. The mesonephric ( $m$ )-gonadal (g) complex from female sheep fetuses. (a) The isolated complex including the kidney (k) from a 40-day-old fetus before dissection. (b) The mesonephros, kidney and ovary from a 40-day-old fetus after dissection. (c) Histological section of a 35-day-old ovary before culture. (d) Histological section of a 35-day-old ovary after 48 h culture. Arrows indicate germ cells; arrowheads indicate necrotic cells. Scale bars represent $1 \mathrm{~mm}(\mathrm{a}, \mathrm{b})$ and $50 \mathrm{\mu m}(\mathrm{c}, \mathrm{d})$.

was due mainly to progressive increases in the mass of the mesonephros. Compared with its mass at day 32, the male mesonephric-gonadal complex at day 45 had increased in mass approximately fourfold whereas, in females, it had increased approximately threefold. At days 35,40 and 45 , the testis was, on average, 1.8-, 3.0-and 2.5-fold heavier than the ovary.

\section{Stervid contents of the mesonephric-gonatal complex}

In preliminary studies to validate the culture conditions, histological examination of the mesonephric-gonadal complex revealed that most of the tissue was viable and not different in appearance from how it was before culture (Fig $2 c, d)$. The geometric mean and $95 \%$ confidence limits for steroid contents in the mesonephric-gonadal complexes at the time of recovery with respect to day of gestation are shown (Fig. 3). There were significant effects of fetal age in both sexes for all steroids ( $P<0.05$ in all instances). In female gonads, the mean contents of all steroids were not significantly different from the assay detection limits before day 35. From day 35 to day 45, the mean progesterone content in the female gonad was not significantly above the detection limit until day $45(P<0.05)$. Moreover, the mean androstenedione and testosterone contents were not significantly different until days 40 (both steroids $P<0.05$ ) and 45 (both steroids $P<0.01$ ), whereas oestradiol was significantly higher from day 35 onwards $(P<0.01$ in each instance). The oestradiol contents increased progressively with age to reach a mean value around 50 pg per gonad at day 45 . For oestradiol, but not for the other steroids, the increase in content at days 35,40 and 45 was more than twofold, threefold and sixfold, respectively, above that of the tissue mass (Figs 1 and 3 ).

In male gonads, the mean contents of progesterone, androstenedione and oestradiol were not significantly different from the assay detection limit at days 28, 30, 32 and 35 of fetal life. The mean progesterone contents remained near the detection limit until day 45 when a significant increase $(P<0.01)$ above the detection limit was noted, as was the case in the female gonad. At days 40 and 45 androstenedione was significantly higher than the detection limit and the mean contents at these times exceeded $200 \mathrm{pg}$ per gonad. In the male gonad, the major steroid from day 35 was testosterone, which increased progressively from approximately $50 \mathrm{pg}$ per gonad at day 35 to approximately 3000 pg per gonad at day 45 of fetal life. The mean content of 

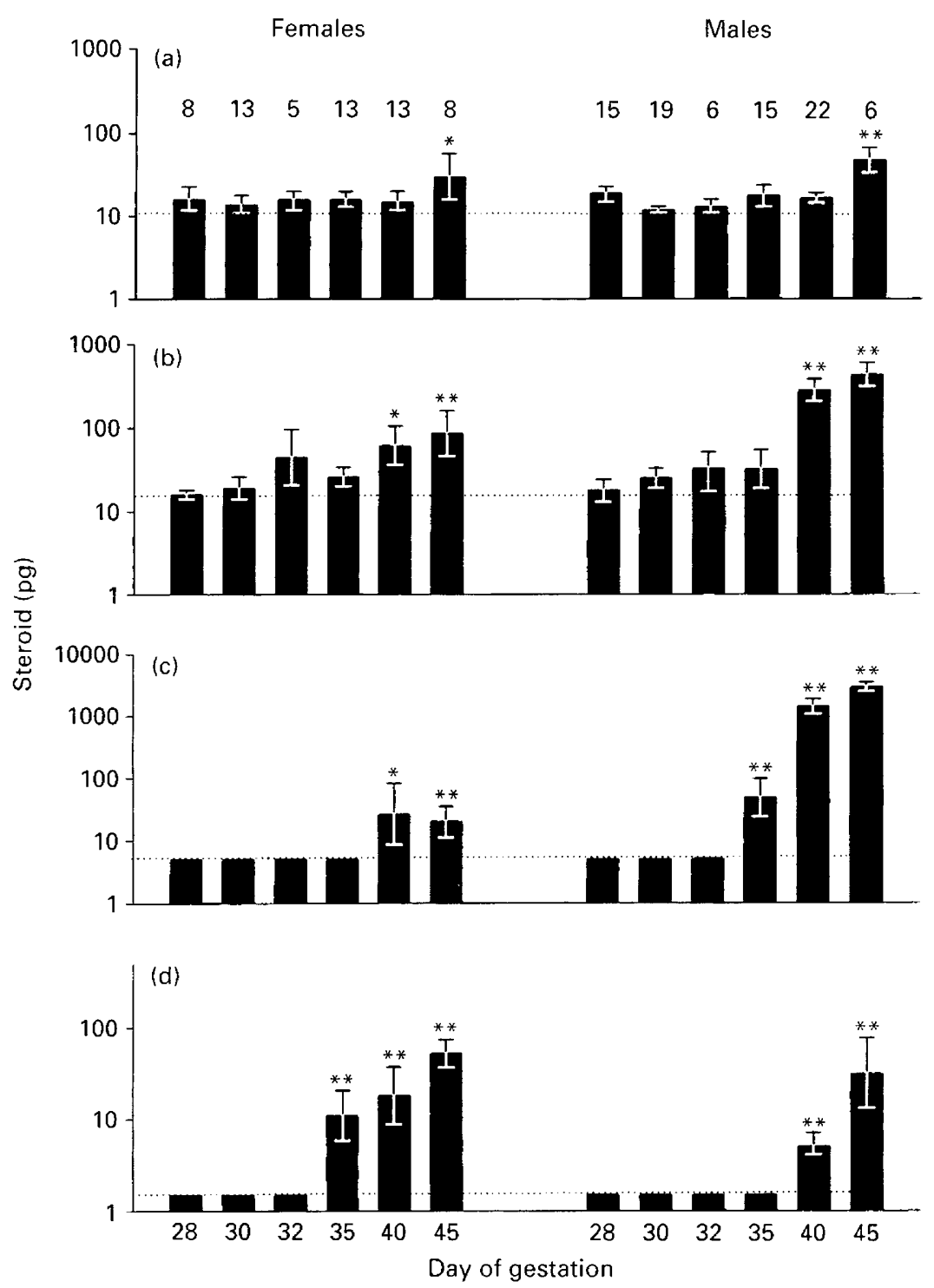

Fig. 3. Content of (a) progesterone, (b) androstenedione, (c) testosterone, and (d) oestradiol in the mesonephric-gonadal complex at the time of recovery with respect to day of gestation of female and male sheep fetuses. Values are geometric means and the vertical bars represent $95 \%$ confidence limits. The dotted line shows the detection limit of the assay. Asterisks indicate that the mean values were significantly higher than the assay detection limit: ${ }^{*} P<0.05 ;{ }^{* *} P<0.01$. Numbers above the histograms refer to the number of tissues studied.

oestradiol in the male gonad was undetectable at day 35 , but significantly higher than the detection limit at day 40 $(P<0.01$; approximately $5 \mathrm{pg}$ per gonad $)$ and day 45 $(P<0.01$; approximately $30 \mathrm{pg}$ per gonad). For testusterone but not for progesterone, the increase in content at days 35 , 40 and 45 was more than fivefold, 40-fold and 50-fold, respectively, above that of the tissue mass (Figs 1 and 3). For androstenedione, the increase above that of tissue mass was only observed at days 40 and 45 and was greater than threefold whereas, for oestradiol, an increase above that of tissue mass was only noted at day 45 and was, again, greater than threefold (Figs 1 and 3).

The geometric mean and $95 \%$ confidence limits for the steroid contents in the media and mesonephric-gonadal complexes after $48 \mathrm{~h}$ culture with respect to fetal age are shown (Fig. 4).

For both male and female tissues, the contents of both progesterone and androstenedione were significantly higher than their respective detection limits at every fetal age studied. The only exception to this was for androstenedione at day 30 in both male and female gonads. For testosterone, the accumulation of steroid was not significantly higher than the detection limit until tissues were recovered at or after day 35 of gestation. For oestradiol, the accumulation was significantly higher in females at every age except day 28 and, in males, at every age except days 28 and 32 of gestation. In females, the major steroids produced after culture were those of androstenedione and oestradiol. When the tissues 

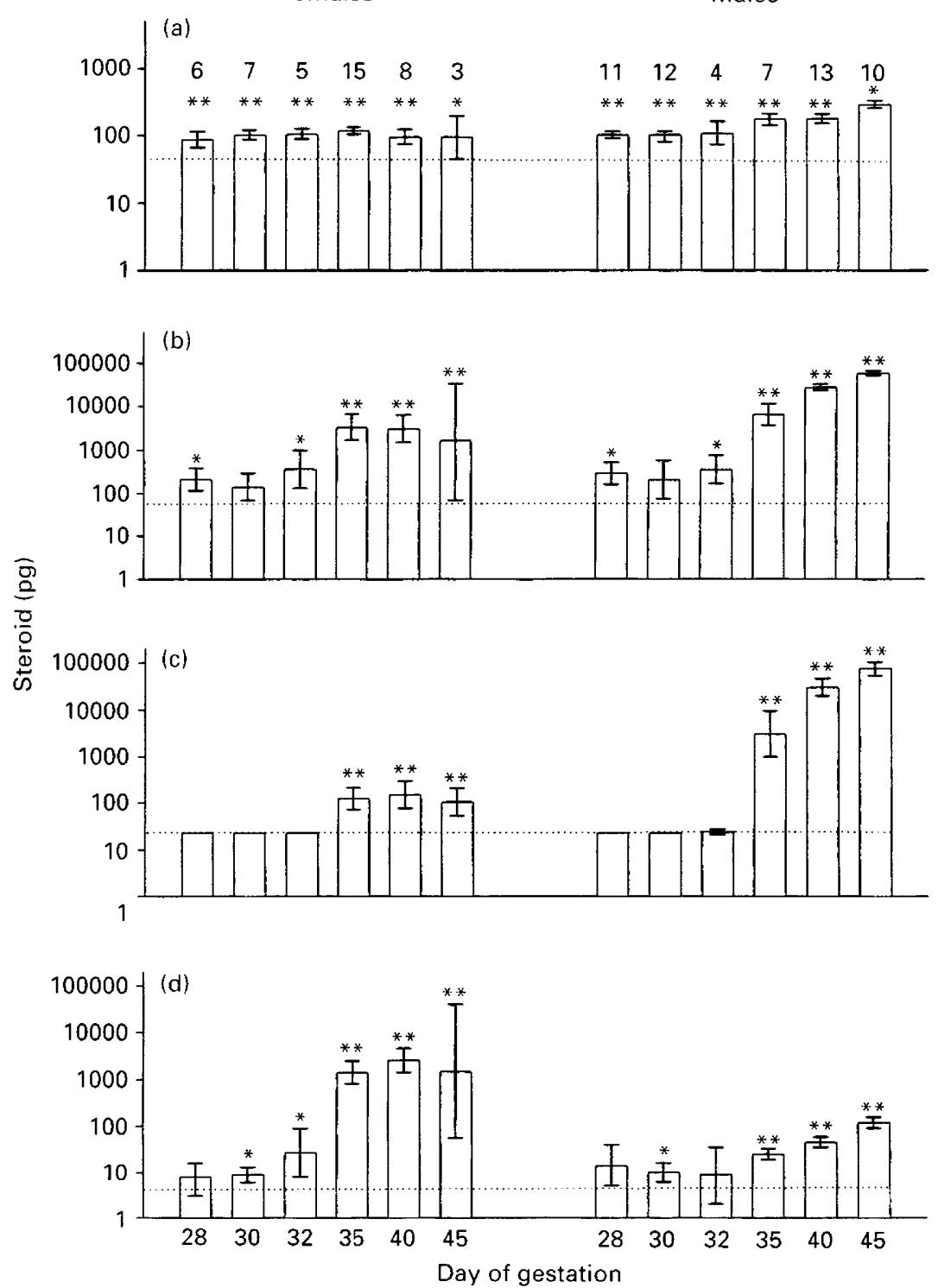

Fig. 4. Content of (a) progesterone, (b) androstenedione, (c) testosterone, and (d) oestradiol in the culture medium and mesonephric-gonadal complex after $48 \mathrm{~h}$ culture with respect to day of gestation of female and male sheep fetuses. Values are geometric means and the vertical bars represent $95 \%$ confidence limits. The dotted line shows the detection limit. Asterisks indicate that the mean values were significantly higher than the detection limit: ${ }^{*} P<0.05 ;{ }^{* *} P<0.01$. Numbers above the histograms refer to the number of tissues studied.

were recovered at days 35,40 or 45 , the accumulation of androstenedione or oestradiol exceeded 1000 pg. In males, the major steroids produced from the tissues recovered at days 35,40 or 45 were androstenedione and testosterone; the contents of both steroids exceeded 10000 pg per culture when recovered at day 40 or day 45 of gestation.

\section{Effect of addition of androstenedione on the ability of the mesonephric-gonadal complex to synthesize oestradiol}

There was insufficient data to test the effects of adding androstenedione at every gestational age. Therefore, the results for day 28 and day 30 were combined, as were those for day 35 and day 40; other gestational ages were not studied (Fig. 5). These results represent the cumulative contents of oestradiol in the media and mesonephricgonadal complexes as geometric means and $95 \%$ confidence limits. In females, the addition of androstenedione to tissues recovered at days 28-30 led to an accumulation of oestradiol which was significantly higher than that in the control cultures whereas when androstenedione was added to tissues recovered at days $35-40$ there was no significant increase above the control. In males, the addition of androstenedione to the mesonephric-gonadal tissue at days 28-30 and 35-40 resulted in a significant increase in Downloaded from Bioscientifica.com at 04/26/2023 11:03:41AM 


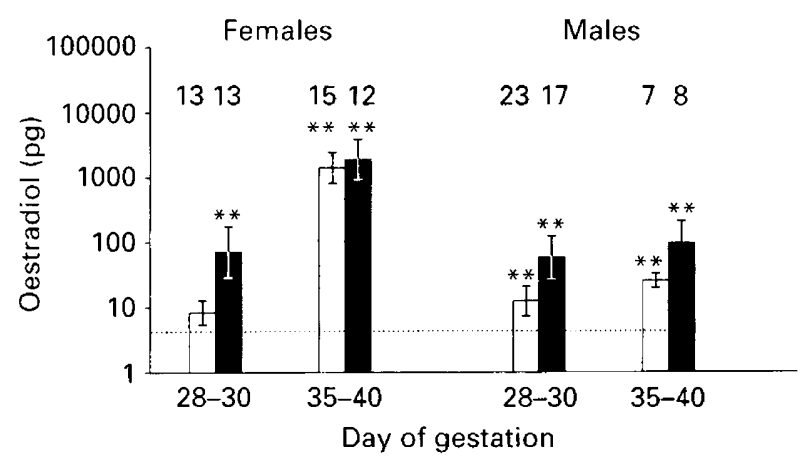

Fig. 5. Oestradiol content in the culture medium and mesonephric-gonadal complex of female and male sheep fetuses after $48 \mathrm{~h}$ culture in the presence $(\square)$ or absence $(\square)$ of supplementary androstenedione $\left(1 \mu \mathrm{g} \mathrm{ml}^{-1}\right)$ with respect to days of gestation. Values are geometric means and the vertical bars represent 95\% confidence limits. The dotted line shows the detection limit. Asterisks indicate that the mean values were significantly higher than the detection limit: ${ }^{* *} P<0.01$. Numbers above the histograms refer to the number of tissues studied.

oestradiol accumulation compared with controls at both age ranges $(P<0.01)$.

\section{Steroid contents of the gonads and mesonephros isolated and cultured separately}

Mesonephric-gonadal complexes were recovered from fetuses at day $35,40,45$ and 55 , and were separated from one another using a dissecting microscope. There were insufficient tissues at some fetal ages to facilitate the examination of age affects and, therefore, results were pooled over all ages. The aim of the present study was to test whether the gonad and mesonephros each had the potential to synthesize steroids. The data showing the geometric mean and $95 \%$ confidence limits for the gonad or mesonephros at the time of isolation are summarized (Fig. 6). The results show that the steroid contents of progesterone and androstenedione from the mesonephros and gonad separately, in both sexes, at the time of recovery were significantly higher than the detection limits $(P<0.05)$. In females, the testosterone contents were not significantly higher than the detection limit in either the mesonephros or gonad; however, testosterone was present in significant amounts in both tissues in males. Oestradiol was present in significantly higher amounts $(P<0.01)$ than the detection limit in the mesonephros of males and females at recovery, and was also detectable in the female but not the male gonad. The data showing the geometric mean (and 95\% confidence limits) with respect to the steroid contents of the media and gonad or mesonephros after $48 \mathrm{~h}$ culture are also shown (Fig. 6). These results show that, with the exception of testosterone in the female mesonephros, the contents of all steroids from the mesonephros were significantly higher than the detection limits, as were those for the cultured gonads. Moreover, the contents of progesterone, androstenedione, testosterone and oestradiol from cultured mesonephric tissue were similar in males and females. In contrast, the steroid profile in the female gonad differed from that in the male gonad after tissue culture. In the testis, the major steroid present was testosterone and, to a lesser extent, androstenedione, whereas there were low contents of progesterone and very low contents of oestradiol (Fig. 6). After culture of the ovaries, the major steroids present were androstenedione and oestradiol. In all instances and for both males and females, the amounts of steroids accumulated in the tissue and media of either the mesonephros or the gonad were significantly higher than the contents in the tissues at recovery $(P<0.05$ in all cases, Student's $t$ test $)$.

\section{Discussion}

The results from the present study of sheep fetuses show that the contents of progesterone, androstenedione, testosterone and oestradiol in the mesonephric-gonadal tissues are not detectable before sexual differentiation, despite the fact that this tissue is capable of synthesizing most of the steroids at this time in zitro. The results also show that after sexual differentiation (that is, after day 32), the mesonephricovarian complex and the mesonephric-testicular complex contained measurable concentrations of oestradiol and testosterone, respectively. Since earlier reports by Attal (1969) and Mauleon et al. (1977) showed that pools of gonads contain detectable concentrations of steroids, the possibility that both the gonads of both sexes synthesize steroids before sexual differentiation cannot be ruled out. Nevertheless, it is worth noting that the detection limits in the present study for progesterone, androstenedione, testosterone and oestradiol were 10, 20,5 and 2 pg per organ, respectively. Moreover, the contents of oestradiol in the female mesonephric gonadal complex and testosterone in the male mesonephric gonadal complex increased at least fivefold at day 35 relative to days 28,30 or 32 of fetal life. The contents of other steroids in the pathway to oestradiol increased progressively in both the male and female mesonephric-gonadal complexes from day 35 through to day 45 of gestation. Thus, although the mesonephric-gonadal complex in females is characterized by relatively high tissue contents of oestradiol and, in males, by high contents of testosterone and androstenedione, the presence of any of these steroids was not exclusive to either sex. The increased mesonephric-gonadal contents of oestradiol in females and of testosterone and androstenedione in males at days 35-40 exceeds the progressive increase in the mass of the tissues over these ages. For example, the mesonephric-gonadal mass at day 45 had increased approximately threefold in females and fourfold in males compared with at day 32 . Over the same time, the oestradiol content in the mesonephric-gonadal complex increased $>25$ fold in females and the androstenedione and testosterone content in males $>30$-fold. Oestradiol, androstenedione and testosterone were the only steroids noted to increase substantially on a per unit mass basis; the mesonephricgonadal contents of other steroids (such as progesterone, androstenedione and testosterone in females and progesterone and, to a lesser extent, oestradiol in males) tended to increase over time principally because of increased tissue mass. 

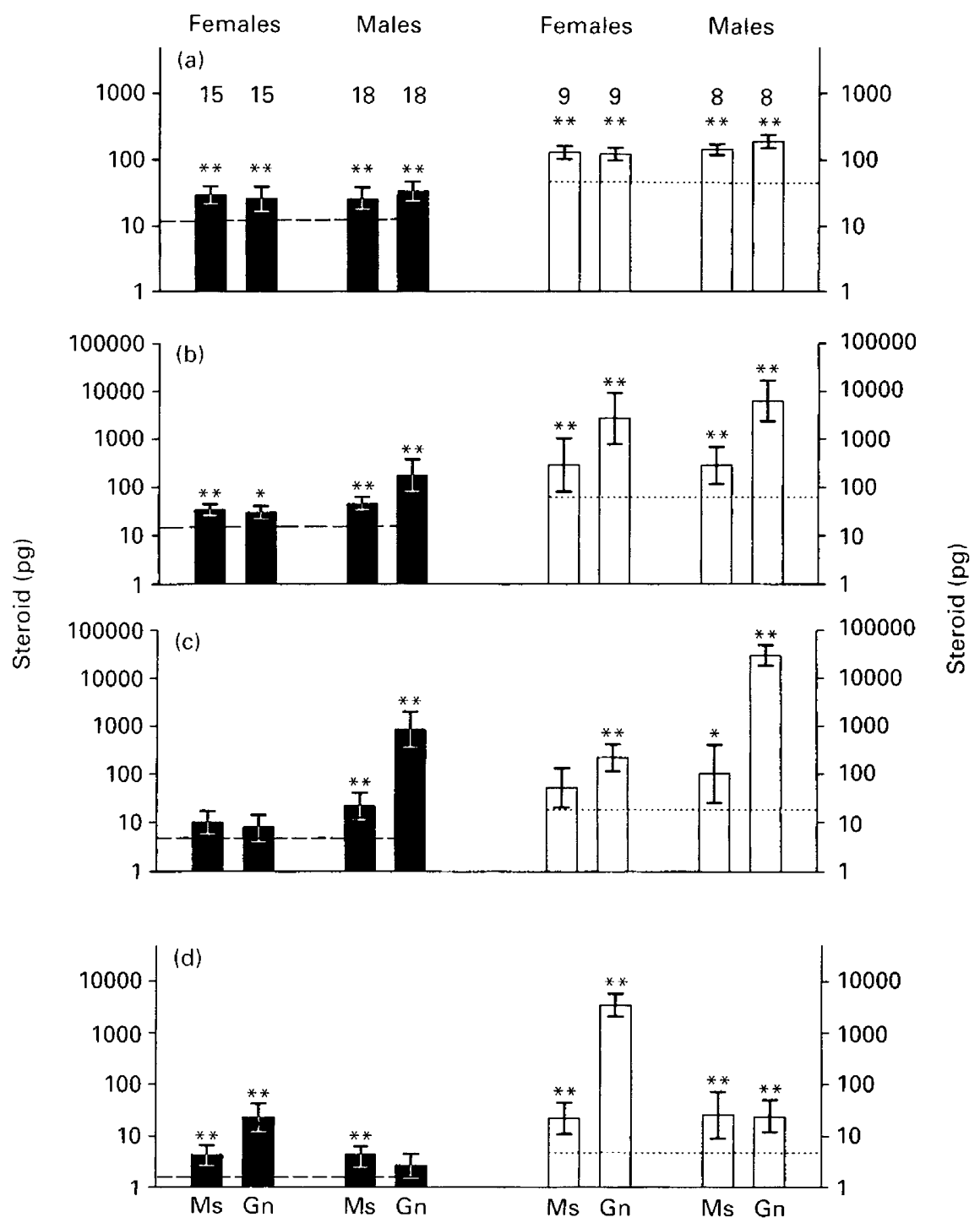

Fig. 6. Content of (a) progesterone, (b) androstenedione, (c) testosterone, and (d) oestradiol in isolated mesonephros (Ms) and gonad (Gn) of female and male fetuses at time of recovery ( $\square$ ) and in the medium and tissue after $48 \mathrm{~h}$ culture ( $\square$ ). Values are geometric means and the vertical bars represent $95 \%$ confidence limits. The dotted line shows the detection limit. Asterisks indicate that the mean values were significantly higher than the detection limit: ${ }^{*} P<0.05 ;{ }^{* *} P<0.01$. Numbers above the histograms refer to the number of tissues studied.

The finding in the present study that the mesonephric-gonadal complex does have the capacity to synthesize some steroids (progesterone, androstenedione and oestradiol) in vitro before sexual differentiation suggests that many of the steroidogenic enzymes in the pathway from cholesterol to oestradiol have developed or are being incluced at this time. In both male and female fetuses at days $28-30$, the addition of androstenedione led to increased oestradiol accumulation, confirming the finding of Payen et al. (1996) that the aromatizing enzyme system is present before sexual differentiation. However, it appears that aromatizing enzyme activity continues to increase after sexual differentiation in females but not in males, accounting for the increased androgen contents in males relative to females. Payen ot al. (1996) used the tritiated water technique to show that the amount of aromatase activity in fetal sheep testis is approximately $10 \%$ that of the ovary at day 49 of fetal life. This finding is consistent with the notion that aromatase activity in females, but not males, increases after sexual differentiation. The present study also suggests that there are regulatory factors present before sexual differentiation that limit androstenedione synthesis, but whether these factors act directly on cholesterol transport, metabolism or steroid enzyme synthesis remains to be determined.

The present study examined whether the mesonephros contained measurable amounts of steroid and whether this tissue was capable of synthesizing steroid. The results show that the mesonephros from both male and female fetuses contained detectable amounts of all steroids except for testosterone in the female. In general, given that the mass of 
the mesonephros was 4-8-fold higher than that of the gonad, the steroids produced per unit mass of mesonephric tissue were lower than in the gonad. No obvious sex differences were noted in the steroid contents of the mesonephros, in contrast to the gonads, where the androstenedione and testosterone content of the testis was higher than that in the ovary, and where the oestradiol content was higher in the ovary. The results from culturing the mesonephros for $48 \mathrm{~h}$ added support to the hypothesis that the mesonephros was steroidogenically active when isolated from the gonad. In all instances, except for testosterone in females, there was an increase in mean steroid accumulation in the media and tissue after culture relative to tissue concentrations at recovery.

The dominant steroids produced in vitro by the mesonephros were progesterone and androstenedione. However, in most cases, as with the steroid contents of the mesonephros at the time of recovery, the contents were lower in the mesonephros than in the gonads and did not differ between the sexes. One interpretation of this is that the proportion of cells in the mesonephros likely to be steroidogenically active is very small and the cells that are active form part of the continuum from the giant nephron to the developing gonad. The steroidogenic activity of the isolated gonads reflected, in part, the pattern evident in the tissue at recovery. After $48 \mathrm{~h}$ culture, the predominant steroids produced by the ovaries were oestradiol and androstenedione, whereas those produced by the testes were testosterone and androstenedione.

In conclusion, the results of the present study establish that the steroids progesterone, androstenedione, testosterone and oestradiol are not present in the mesonephric-gonadal complex in detectable amounts until after sexual differentiation, that is, day 35 of gestation. The results also suggest that some, if not all, the steroidogenic enzymes in the pathway from cholesterol to oestradiol are present before sexual differentiation but that the supply of steroid precursor at some point before androstenedione is limiting. The major steroids present after sexual differentiation are oestradiol and androstenedione in females and testosterone and androstenedione in males. The major source of these steroids was confirmed to be the gonad; however, the mesonephros was confirmed as a tissue with measurable contents of steroid and also capable of steroidogenesis in vitro.
The authors thank D. Jensen and R. Bailey for management of the sheep flocks, G. Shackell for assistance with the embryo transfer experiments and the New Zealand Foundation for Research, Science and Technology for financial support.

\section{References}

Attal J (1969) Levels of testosterone, androstenedione, estrone and estradiol$17 \beta$ in the testes of fetal sheep Endor rinology $85280-289$

Buehr M, Gu S and McLaren A (1993) Mesonephric contribution to testis differentiation in the fetal mouse Drolopment 117 273-281

Byskov AG (1978) The anatomy and ultrastructure of the rete system in the fetal mouse ovary Biology of Reprotuction 19720-735

George FW and Wilson JD (1988) Sex determination and differentiation. In The Physiology of Reproduction pp 3-25 Eds E Knobil and J Neill. Raven Press Ltd, New York

Jost A (1947) Recherches sur la differenciation de l'embryon de lapin II. Action des androgenes synthesc sur l'histogenses genitale Archive's d'Anatomic Micrescopique et de Morplologie Experimentale 36 242-270

Jost A (1953) Problems in fetal endocrinology. The gonadal and hypophyseal hormones Recent Progress in Hormone Resenrch $8374-418$

McNatty KP, Kieboom LE, McDiarmid J, Heath DA and Lun S (1986) Adenosine cyclic 3',5'-monophosphate and steroid production by small ovarian follicles from Booroola ewes with and without a fecundity gene Jourmal of Reproduction and Fertility 76 471-480

McNatty KP, Smith P, Hudson NL, Heath DA, Tisdall DJ, O W-S and BrawTal R (1995) Development of the sheep ovary during fetal and early neonatal life and the effect of fecundity genes lownol of Reprotiction and Fertility Supplement 49 123-135

Mauleon P, Bezard J and Terqui M (1977) Very early 17 beta-estradiol secretion by fetal sheep ovary in zitro study Amales de Biologile Animinle Biochomie Biophysiqu' $17399-401$

Payen E, Pailhoux E, Abou Merhi R, Gianquinto L, Kirszenbaum M, Locatelli A and Cotinot C (1996) Characterization of ovine Sry transcript and developmental expression of genes involved in sexual differentiation International Joumal of Developmental Biology 40 567-575

Peters $H$ and McNatty KP (1980) The development of the wary and in embryo. In The Oiary pp 1-10 Eds H Peters $H$ and K MeNatty. Granada Press, London

Sarkar FH, Li Y-W and Crissman JD (1993) A method for PCR secuencing of the p53 gene from a single $10 \mu \mathrm{m}$ frozen as paraffin-emberded tissue section BioTechmiqu's 15 36-38

Sweeney T, Saunders PTK, Millar MR and Brookes AN (1997) (Intogeny of anti-Müllerian hormone, $3 \beta$-hydroxysteroid dehydrogenase and androgen receptor expression during ovine fetal gonadal development foumal of Entocrinology 153 27-32

Zamboni L, Bezard J and Mauleon P (1979) The role of the mesonephros in the development of the sheep fetal ovary testis Aninles de Biologic Animale' Biochenie Biophysiqu' 19 1153-1178

Zamboni L and Upadhyay $\mathbf{S}$ (1982) The contribution of the mesomephros to the development of the sheep fetal testis American foumal of Anatomy 165 $339-356$ 